\title{
A review of fingerprint recovery within an arson crime scene
}

\begin{abstract}
Fingerprints have been used in criminal investigations in the United Kingdom since 1902. ${ }^{1}$ Many advances in research and technology have improved current opportunities for fingerprint recovery at crime scenes. Possibly due to the lack of training and research, the recoverability of fingerprints in a fire scene are undervalued and misunderstood. There is a widespread misconception that fire will destroy all fingerprint evidence. Evaluation of current literature available has shown that fingerprints can indeed be recovered with excellent results. Fire scenes, in particular deliberate or arson, can be examined with reference to the elevated temperature conditions at each stage and the understanding of the soot removal techniques is paramount to the investigation process. Further research is required to make advancement in fire scene fingerprint recovery.
\end{abstract}

Keywords: latent fingerprints, fingerprints, soot removal, elevated temperatures, arson investigation, destructive scenes
Volume 6 Issue 5 - 2018

\author{
Andrew O'Hagan, Rosalee B Banham \\ Department of Science and Technology, Nottingham Trent \\ University, United Kingdom
Correspondence: Andrew O'Hagan, Nottingham Trent University School of Science \& Technology
Clifton Lane, Nottingham, NGII 8NS, Direct Line 0II58483 I53,
United Kingdom, Tel +44I I 58483 I 53 ,
Email andrew.ohagen@ntu.ac.uk \\ Erasmus Darwin, Room 230, Nottingham Trent University,
}

Received: August 09, 2018 | Published: September 04, 2018

\section{Introduction}

This review will explore the possibilities of fingerprint recovery in an arson investigation. Fingerprints are patterns observed on a surface where unique ridge detail can be seen. Ridge detail is small grooves and hills on all an individual's fingertips, palms and soles of feet. ${ }^{2}$ The ridge detail patterns are unique and used for identification, ${ }^{2}$ as the chance of two individuals possessing the same fingerprint ridge detail patterns is believed to be 64 billion to one. ${ }^{3}$ An instance of two individuals with the same fingerprint has never been recorded. ${ }^{1}$ Fingerprints were first used in criminal investigations in $1902 .{ }^{1}$

William Harper ${ }^{4}$ first explored recovering fingerprints from a fire scene. Research is limited, but fingerprints found are increasingly relevant and depending on the item may link a suspect to a scene. ${ }^{5}$ The components of the ridge detail behave differently when exposed to elevated temperatures, soot and water from extinguishing. Understanding of the relevant conditions assist investigators in determining where to look and the best method of recovery of evidence. The misconception that fingerprints cannot be recovered from a fire scene may have derived from the investigators lack knowledge where to look. ${ }^{6}$

Fire dynamics indicate how different factors interact to influence the way a fire behaves and are studied to aid investigation strategies. Chemistry, fire science, engineering, fuel dynamics and heat transfer all contribute. ${ }^{7}$ The elements that affect a fire are oxygen, fuel, heat and chemical reaction. ${ }^{7}$ It is necessary to understand this to detect fingerprints at the scene. Fire investigators will assess damage, burn patterns and post fire indicators to determine the source of the fire 7,8 and diagnose whether it was deliberately caused or not. Items often become unrecognisable and a layer of sooty black deposits form upon the surfaces. Understanding this can aid in the recovery of evidence as the soot can protect surfaces and preserve fingerprints. ${ }^{6,9,10}$

\section{Discussion}

\section{Arson:The Law}

The main legislation surrounding arson is the Criminal Damage Act 1971. This involves an individual recklessly damaging or destroying a property belonging to themselves or another without lawful reason to. When criminal damage is committed by use of fire it is defined as Arson. The areas of this act are split into two sections of relevance within this literature - Arson Endangering Life; and, Arson not Endangering Life. An 'Arson Endangering Life' charge does not require actual injury to take place or the requirement for an attempt to kill, but, requires for life to be endangered. If there was a direct attempt to kill, the crime would be classed as murder (class 2) ${ }^{11}$ It requires - a person to have no lawful excuse to damage any property; reckless to the extent that life would be endangered; and, reckless to whether property would be damaged or destroyed. If an individual were to be convicted for this offence they would be liable for a maximum sentence of imprisonment for life. ${ }^{12}$ "Arson not Endangering Life' requires a person without a lawful excuse to damage any property and to be reckless to whether the property would be destroyed or damaged. If an individual were convicted they would be liable to a maximum sentence of ten years. This includes - criminal damage not endangering life; possession of anything with intent to damage or destroy property; and, threat to damage or destroy. ${ }^{11,12}$

Other acts to be aware of include;

\section{a. Crime and Disorder Act 1998}

b. Anti -Terrorism, Crime and Security Act 2001

c. Explosive Substances Act 1983

\section{Statistics}

Figure 1 shows the distribution of deliberate fires is heavily weighted with secondary fires. Secondary fires are those in derelict buildings, chimneys, outdoor grassland, gardens and refuse. The other categories listed in Figure 1 are considered primary fires. ${ }^{13}$ From 2010 to 2017 the percentage of deliberate fires overall for the year ranged from $44 \%$ to $52 \%$ of total fires recorded by the fire and rescue service. This is a significant proportion of the fires reported each year (Table 1). Figure 2 shows that over the 18-year period between 1999 and 2017, a significant decrease in deliberate fires can be identified. Chimney fires were not considered a deliberate fire until 2009/10. This category is not stated in the graph as the number does not exceed 40 for each year. In addition, the recording system was generated manually on a paper form up until 2009 and as such, was possibly less reliable. However, it is unlikely to be the cause of the decrease in total deliberate fires. ${ }^{15}$ It can possibly be explained by constant development in the field of 
fire such as improvements to the criminal investigation system and technological advances in DNA, fingerprints, CCTV and general investigation strategy. The number of deliberate fires in 2016/17 had decreased by $50 \%$ since $2006 .{ }^{16}$ Advances in the future, such as, possibilities of the recovery of fingerprints in a fire scene may further help to decrease the total number of deliberate fires especially as arson is one of the most cost impactful crimes. ${ }^{17}$ Once the possibilities are better understood that fingerprint and DNA recovery are possible to detect in a fire scene, this may deter offenders from using fire as a method of concealment.

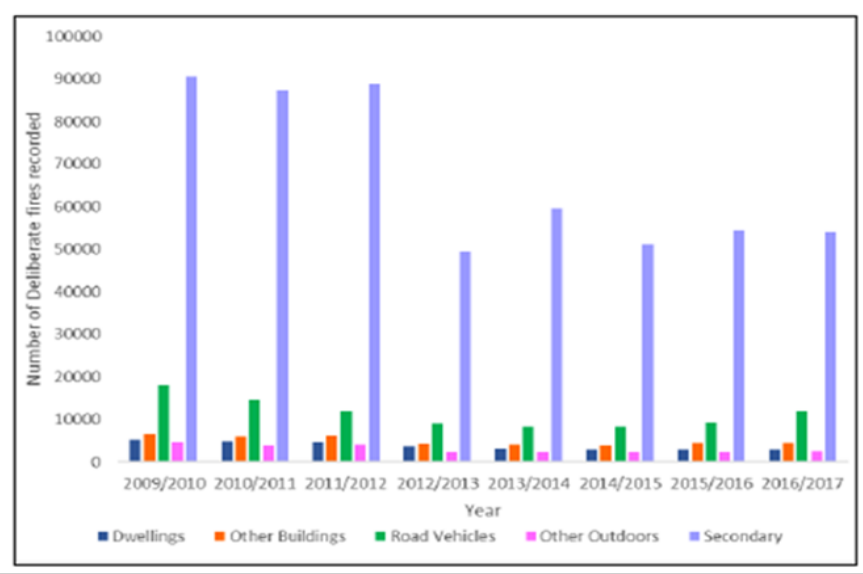

Figure I Graph to show the relation of the categories of deliberate fires from 2009 to $2017 . .^{13}$

Table I The percentage of deliberate fires in the total number of fires reported for the years 2010 to $2017^{13,14}$

\begin{tabular}{ll}
\hline Year & Percentage \\
\hline $2010 / 11$ & 51.22 \\
$2011 / 12$ & 51.68 \\
$2012 / 13$ & 44.64 \\
$2013 / 14$ & 45.33 \\
$2014 / 15$ & 44.2 \\
$2015 / 16$ & 45.41 \\
$2016 / 7$ & 47.02 \\
\hline
\end{tabular}

It would be reasonable to want to compare the Home Office fire and rescue statistics to the conviction rates of arson. Unfortunately, this cannot be performed efficiently as arson is not a crime of its own, but, falls into the category of criminal damage. From a crime scene investigation perspective, a fire or arson may be classified as - criminal damage; arson/fire; arson with intent to endanger life; fire non-crime; suicide; burglary damage; vehicle; manslaughter; attempted murder; and, murder. ${ }^{18}$ It is difficult to quantify and obtain accurate incident data. It is easy to misidentify the cause of fires and the statistics may not accurately represent the distribution of fire types. ${ }^{7}$ In the year of June 2014 to June 2015 the police incident data recorded 20576 specific arson incidents. ${ }^{19}$ However, the fire and rescue service recorded 68526 deliberate fires. ${ }^{15}$ The police data has only classified as arson $30 \%$ of the incidents the fire and rescue department considered deliberate. It is known that in 2004/05 only $9 \%$ of arson cases resulted in a conviction. ${ }^{13}$ In 2003 the cost of deliberate fires was believed to have cost the economy $£ 2.8$ billion. ${ }^{13}$ It can be seen from Figure 2, 2003 is the highest peak on the graph.

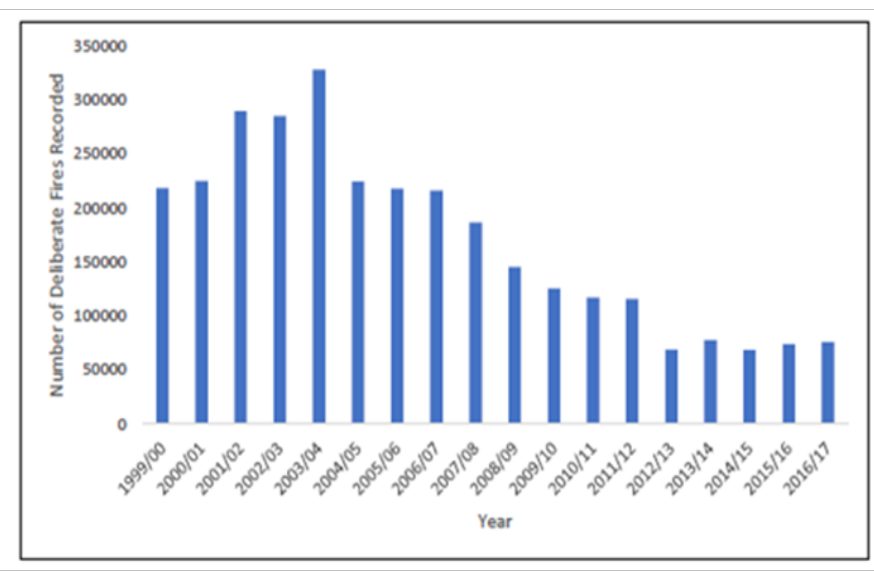

Figure 2 The number of deliberate fires recorded from 1999 to $2017 .^{13}$

\section{Soot and the stages of a fire it is generated}

As soot is often produced by fire it would bereasonable to explore how soot effects fingerprints. When a fire has reached an intense phase, soot can deposit on items. Soot deposits may act as a protective shield to the fingerprint from the intense heat and extinguishing. ${ }^{10}$ There are several different phases a fire will reach and the level of soot deposition and damage can give an indicator to the phase the fire may have reached before becoming extinguished to understand the possible temperature exposure. Commonly there are four phases of a fire-incipient; emergent smouldering; fully developed; and oxygen regulated smouldering. Incipient is the first phase of burning. This may last from one hour to several days. Little smoke is generated at this stage. ${ }^{7}$ During emergent smouldering or growth the temperature of the room will increase slightly and flames will reach $1000^{\circ} \mathrm{C}$. During the fully developed fire stage the temperature will continue to increase until items reach ignition temperature. This is the minimum temperature a fuel will spontaneously ignite. This causes flashover to occur where flames spread over simultaneously, commonly, when the ceiling temperature is $500^{\circ} \mathrm{C}$ to $600^{\circ} \mathrm{C}$. The fire may not reach the flash over stage. The temperature of the room will increase. Heat from the origin is converted into the higher points of the room where it accumulates and radiates downward. ${ }^{7,20}$ The heat impact to fingerprints is reduced at lower points of the room. During the flashover the soot and smoke are commonly consumed as fuel and in this circumstance the protected fingerprints can become exposed.

The nature of a fire requires oxygen to burn. When there is not sufficient oxygen for the fire carbon and carbon monoxide are produced instead of carbon dioxide. This is known as incomplete combustion. The carbon by-product produces soot. This formation of soot will deposit onto surfaces in the scene and possibly protect a fingerprint from the direct impact of the intense heat. ${ }^{6,9}$ It is unlikely that fingerprints will be recovered directly from the origin. ${ }^{10}$ Oxygen regulated smouldering or decay will follow when the oxygen supply is depleted or limited. The room will reignite if a new source of oxygen is introduced, such as, opening a door or breaking a window. The room will fill with dense smoke and gases and the temperature of the room can reach over $1000^{\circ} \mathrm{C}$. In this circumstance self-extinguishment may occur due to deficit of oxygen resulting in the room being covered in soot. The smoke and soot is a source of fuel that can be used by the fire under suitable conditions. This is known as oxidation. The carbon in the soot is oxidised into gases removing it from the surface causing 
clear zones. The longer the exposure to the heat and the higher the temperature of the room, the more obvious the effect of oxidation. ${ }^{20}$

\section{Fingerprint deposit components}

The understanding of how a fire, elevated temperatures or water may affect the components of a fingerprint is important and ensures that the most beneficial enhancement techniques are used without destruction of the fingerprint. Eccrine glands secrete 98\% water, the remaining $2 \%$ consists of mineral salts, sugars, urea and organic acids. These glands are located on the palms, fingertips and soles of the feet. ${ }^{5} \mathrm{~A}$ fingerprint with only eccrine components is considered a clean print. ${ }^{21}$ Factors that will affect eccrine secretions depend on the individual's age, sex, diet and physical condition. ${ }^{2}$ Sebaceous glands are found all over the skin except for the palms, fingertips and soles of the feet, often in areas with hair such as the armpit or head. The fingerprint deposit may be contaminated with sebaceous material by touching the face or hair. Sebaceous material is organic and consists of fatty acids, glycerides, hydrocarbons and alcohols, most of which are insoluble in water. ${ }^{5}$ The components are highly variable between individuals, one study found 300 different sebaceous constituents. ${ }^{21}$

Apocrine gland contamination of a fingerprint is less likely. The glands can be found in the armpit, groin and perineal area. The components include iron, water, proteins, carbohydrates and sterols. A contamination with these components may be relevant in a case involving violence or rape. ${ }^{5}$ The quality of the initial fingerprint deposit is dependent on the pressure applied to the surface known as the substrate, components and sweat excreted by the individual, nature of the substrate and the time in contact with the substrate. ${ }^{22}$ If a surface is porous it increases the surface adhesion due to the increased surface area. ${ }^{5}$ The amount of sweat on the individual may be influenced by stress or heat, both of which are relevant. Stress is likely to occur when the offence is taking place and if the individual is present for a time when the fire is alight then the temperature of the environment may increase. ${ }^{22}$ If the quality of the print before the fire was poor then it is likely the recovery of fingerprints will not be possible. ${ }^{23}$ The longer the exposure the fingerprint has to the intense conditions, the lower the quality of ridge detail the fingerprint displays. ${ }^{24}$ Amino acid components of a fingerprint deposit are believed to begin to show degradation at $100^{\circ} \mathrm{C}$ and further degradation at $150^{\circ} \mathrm{C}$, to which they are unidentifiable, with no evidence of decomposition products. This is conflicted by Clutter ${ }^{25}$ that stated they may be detectable up to $500^{\circ} \mathrm{C}$. Lactic acid degradation is believed to start at exposures of $50-100^{\circ} \mathrm{C}$ and its photo-oxidation product - Pyruvic acid- showed the same results. Thermal decomposition of Urea is initiated at $150^{\circ} \mathrm{C} .^{21}$ At exposures of $700-900^{\circ} \mathrm{C}$ blood will turn black and flaky and burn off completely. This is something to be aware of when investigating areas of the fire that are suspected to have reached these temperatures. This can be determined from the predicted stage at which the fire was extinguished. ${ }^{26}$

The majority of water in a fingerprint deposit will be rapidly evaporated when exposed to excessive heat and proteins are likely to be denatured into soluble amino acids. Oils may survive in the beginning, however, will evaporate when exposed to prolonged heat. ${ }^{7}$ The most fire-resistant component of the fingerprint deposit is salt, however, salt is soluble in water and may be exposed to water during fire extinguishing and in turn possibly damaging the fingerprint. ${ }^{17,27,28}$ In a normal situation in which fingerprints are deposited they begin to deteriorate and will lose distinctness. Factors that affect the rate that this occurs are evaporation of the volatile components such as water, diffusion through and over the substrate and light or heat induced chemical breakdown. ${ }^{5}$ Exposure to fire will increase these factors, resulting in an increase in the rate that the fingerprint will lose clarity and definition. It is found that fingerprints are able to survive the harsh conditions, and with the correct treatment and precautions an identifiable fingerprint may be obtainable. It is recommended that a fingerprint is processed as soon as possible to minimise the deterioration. ${ }^{29}$ Often the investigation attendance is several days after the incident. This timeframe poses a risk to the possibility of fingerprint recovery. ${ }^{23}$

\section{Soot removal techniques}

Soot removal is the process of removing soot from a surface that may expose further information, fingerprints, or blood stain evidence. ${ }^{9}$ The method of soot removal depends on the surface. Aspects to consider include - damage, temperature exposure, duration of heat exposure, texture and porosity. Soot removal is less effective on textured items as it is difficult to remove the soot from the grooves. ${ }^{30}$ Fingerprints that are enhanced on clean surfaces show better quality results than those that have undergone soot removal..$^{30}$ The removal of soot may be necessary prior to treatment with the enhancement agents. The level of soot removal required is dependent on the intended enhancement treatment to follow. If the process of removing soot is not fully understood it may be detrimental to a valuable fingerprint within the scene. There are various methods described in Table 2 each with advantages and disadvantages. A combination of techniques may be beneficial..$^{31}$ If it is unsuitable to treat the entire scene and latent fingerprints are not visible under the soot it may be necessary to identify and target key relevant areas or items..$^{32} \mathrm{~A}$ believed petrol bomb fragment would link the suspect to the scene and possibly to the source of ignition. ${ }^{23}$ Figure $3 \&$ Figure 4 demonstrate some of the techniques for soot removal. It can be seen in Figure 5 that the action of brushing to remove the soot deposits has acted in the same way as powdering a latent fingerprint in a crime scene with aluminium powder.

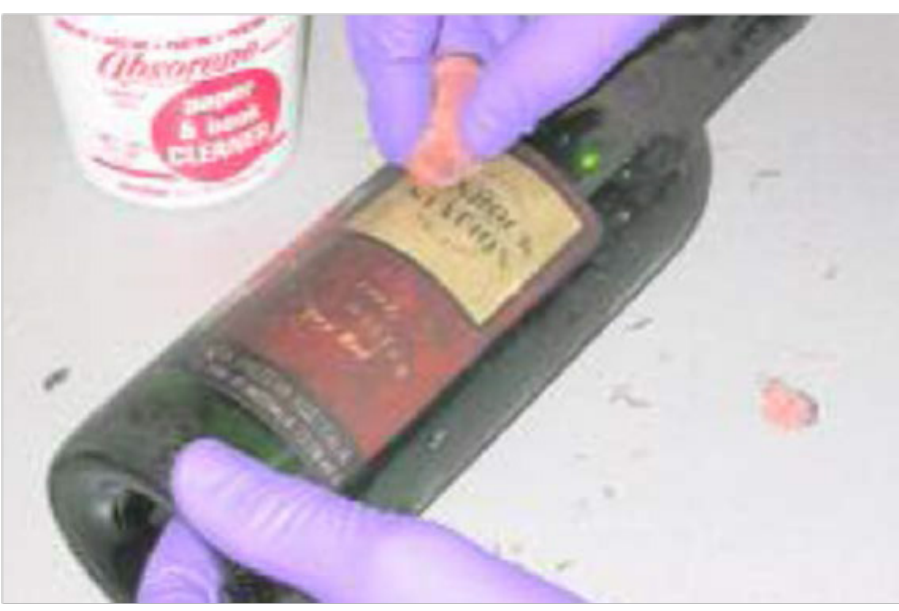

Figure 3 Soot removal technique 'Absorene', applied to a soot covered bottle. ${ }^{30}$

\section{Adaptations to normal enhancement techniques}

It is important to be aware of the circumstances and condition an item or substrate may have undergone to recognise what treatment will be the most effective. The fingerprint may be subjected to many different conditions depending on - their location in relation to the fire; whether the fingerprints were exposed to water during extinguishing 
efforts; and, whether they were exposed to soot. The components that would normally be targeted may not be in the same condition as they would be when recovered from a normal crime scene. Understanding the target components and the conditions that may affect them will allow the investigator to identify the most appropriate technique. Techniques suitable for use on item exposed to fire conditions are evaluated in Table 3. As arson is commonly used as a method of concealment of a more serious crime. It is important to understand the way blood would behave in such an environment, especially when a fingerprint can be made in blood. ${ }^{26}$ Heme protein dyes will stop working at $100-150^{\circ} \mathrm{C}$ which is before protein specific dyes at $200^{\circ} \mathrm{C}$ when treating fingerprints in blood. This indicates the Heme protein in the red blood cells will denature before the protein components in the plasma of the blood. When fingerprints made in blood are exposed to temperatures over $200^{\circ} \mathrm{C}$ it is not possible to determine they were made in blood originally. ${ }^{26}$ Fingerprints in blood can be detected up to $900^{\circ} \mathrm{C}$. Further research may be required to determine whether the amount of blood deposited on the surface will affect the quality of results. ${ }^{26}$

Table 2 A comparison of the most recommended soot removal options

Technique

Technique

This is the most recommended technique among
sources.

\section{Liquid Latex}

Currently used by Metropolitan Police. ${ }^{33}$

Easy to apply, inexpensive, delicate on surfaces, minimal risk of damage to fingerprint, can be applied at either the scene or laboratory. ${ }^{9}$

Can be used to treat entire scene, can be sprayed or dipped.

Latex is quick to dry providing layer is thin and it can be repeated until the desired result is achieved.

A compressor system can be used to apply consistent layers.

A colorant may be added to indicate where it has been sprayed as it dries transparent. ${ }^{9,33}$

Does not require washing or soaking which prevents contaminating other areas. ${ }^{33}$

Does not affect DNA profile, ${ }^{33}$ however, individual brand and formula will need to be checked as many options available. ${ }^{9}$

Soft brush is commonly used equipment by CSI's.

Light Brushing

Little skill or training required.

May be used as a preliminary technique or in conjunction with another e.g. water powered vacuum. ${ }^{23}$

Equipment commonly used by CSIs at scenes.

Tape Lifting

Little training or experience required.

Can be performed several times until desired amount of soot or no further deposits are removed, normally three repeats.

- Scotch tape is preferred as it is less likely to tear, more flexible and has better surface cohesion than J-LAR. 9

Involves rubbing a soft eraser over area of interest. ${ }^{17}$

\section{Disadvantages}

- If layer is applied too thick, 'skinning over' effect may occur which if removed prematurely can damage the underlying evidence. ${ }^{33}$

- The use of thinning agent is not recommended as it may soak through soot layer and bind to underlying components of fingerprint, causing damage when lifted..$^{34}$

Some sources state no residue is left that will affect further treatments, ${ }^{33}$ others state that residue is left, ${ }^{17}$ this may need to be clarified.

At risk of removing substrate if not enough soot is present e.g. clear area. ${ }^{25}$

May peel away evidence, so, removed latex should be examined immediately.

Removed latex cannot be stored. ${ }^{9,30}$

Not suitable for upright glass as it was found to slide down. ${ }^{25}$

Not suitable for detonated accelerant bottle debris. ${ }^{32}$

Cannot remove heavy deposits, ${ }^{17}$ may be used as a preliminary technique. ${ }^{30}$

Not suitable for entire scenes, intended for smaller smooth and simple shaped items or surfaces.?

Care should be taken when fingerprint is visible to avoid premature lifting, before the fingerprint is of value. ${ }^{32}$

Highly destructive technique, only suitable if the fingerprint appears 'baked on'. 
Table Continued

\section{Technique}

Pencil eraser

Ultrasonic bath Sonication

Sodium Hydroxide wash

Water

Silicone casting compound

'Absorene'

\section{Advantages}

Effective soot removal option for heavy deposits.

'Touline' has been found to be the most suitable medium for the bath. ${ }^{35}$

Can be applied with a plastic wash bottle or bath, it is an effective method for heavy soot deposit removal. ${ }^{17}$

- If blood is suspected, the use of 5-Sulphosalysilic acid fixing spray is recommended before application. ${ }^{36}$

Can be used on detonated incendiary bottles. ${ }^{23}$

- Some studies use a sprinkling approach ${ }^{24}$ and others use a smooth flow of clean water. ${ }^{32,10}$

- May be used after brushing to enable better contrast of the fingerprint to the surface for photographing. ${ }^{37}$

‘Isomark' is available in a sprayable version. ${ }^{9}$

- Easy to use, suitable for use on burn victims dehydrated fingertips, ${ }^{38}$ and complicated shapes.

Effective technique for fingerprints in blood on a non- porous surface. ${ }^{17}$

Can be repeated. ${ }^{9}$

-A dough-like substance specifically marketed for soot removal.

Suitable for porous substances when the constituents diffuse into the substrate.

More delicate than liquid latex for paper. ${ }^{34}$

Suitable for fingerprints made in blood on porous surfaces. ${ }^{17}$

\section{Disadvantages}

-Stop immediately if fingerprint begins to degrade. ${ }^{9}$

Not suitable for large areas, but for small items or areas.

- This technique involves soaking in a bath, therefore size of item is limited.

Not suitable for treatment at scene. ${ }^{17}$

Not recommended for fingerprints contaminated with accelerant. $^{32}$

Risk of fingerprint becoming destroyed.

Water not recommended as medium. ${ }^{17}$

- Technique is detrimental to DNA or ignitable fluid recovery, ${ }^{25,33,30}$ fingerprints in blood may dissolve. ${ }^{26}$

Not suitable for large areas..$^{33}$

May damage fingerprint. ${ }^{31}$

Not suitable for fingerprints doused with accelerant. ${ }^{32}$

Detrimental to the most heat resistant components such as salts, which are water soluble.

Not suitable to treat entire scene as it may contaminate other areas, recovery to a laboratory may be required.

Not suitable for porous substrates when the fingerprint is made in blood. ${ }^{17}$

Not suitable to treat an entire scene, suitable for small objects or areas. $^{30}$ 
Table 3 Comparison of some of the suitable enhancement treatment options

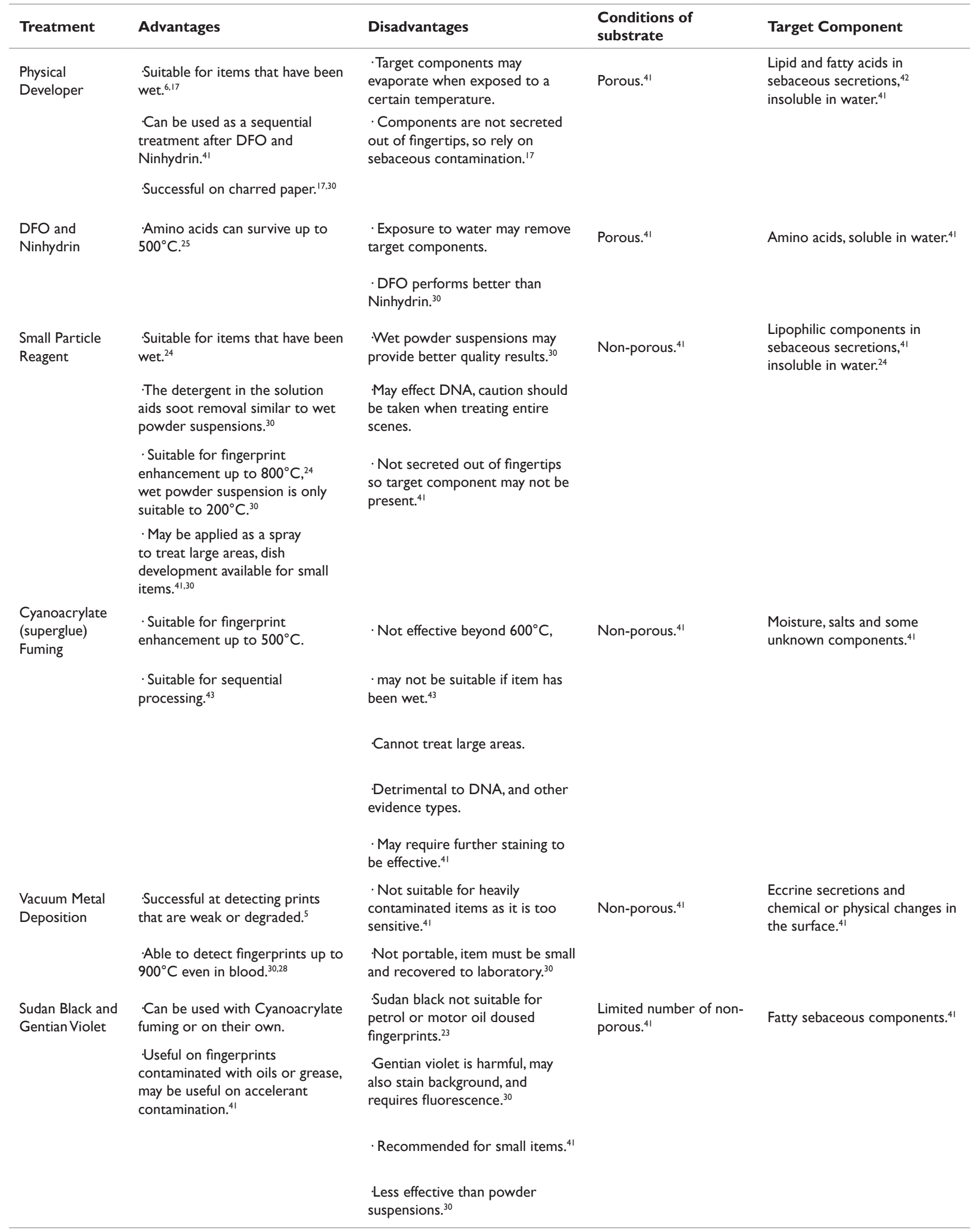



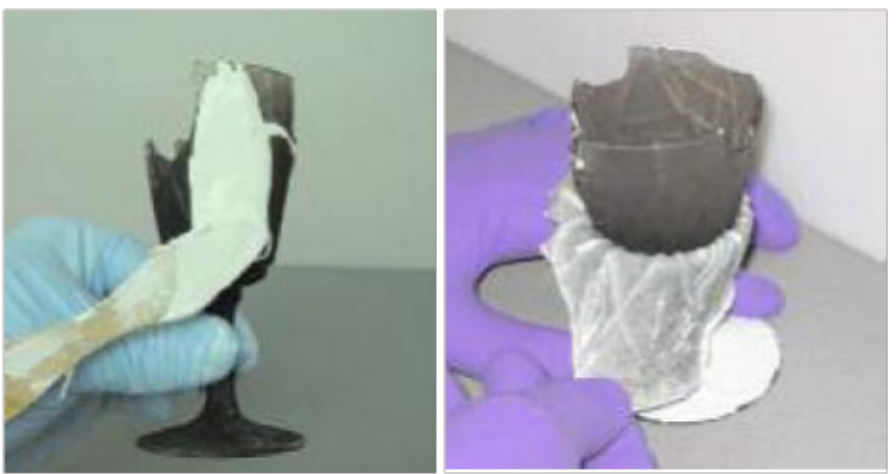

Figure 4 (left) Application of 'Mikrosil' paste, (right) removal of 'Mikrosil'. ${ }^{30}$

Considerations will need to be made with regards to treating items that have been in contact with inflammable liquid as it can dissolve the fatty constituents of the fingerprint. Small Particle Reagent, Cyanoacrylate Fuming and silver black Powder are the most suitable treatments for glass surfaces exposed to accelerant liquids. ${ }^{40}$ Glass exposed to gasoline prior to heat exposure has a detrimental effect on the number of fingerprints that can be recovered..$^{35}$ Ninhydrin, 1,8, Diazafluorenone (DFO) and Physical Developer have been found to work successfully if the fingerprint has been contaminated with accelerant (Figure 5) (Table 3). ${ }^{30}$ Techniques that are normally used for fingerprint enhancement may need to be adapted to make them more efficient for fingerprints exposed to higher temperatures. Molybdenum Disulfide $\left(\mathrm{MoS}_{2}\right)$ is the most common base for Small Particle Reagent; however, other options are available with fluorescent qualities including bases of - Titanium Dioxide $\left(\mathrm{TiO}_{2}\right)$, Zinc Carbonate $\left(\mathrm{ZnCO}_{3}\right)$, and Zinc Oxide $(\mathrm{ZnO})$. Aluminium foil was the only substrate tested in a study to produce quality fingerprints at $800^{\circ} \mathrm{C}$, obtainable with the Titanium Dioxide formula. The Zinc Carbonate formula was successful up to $700^{\circ} \mathrm{C}$ for glass and black ceramic tiles. The Zinc Oxide formula was only suitable up to temperatures of $600^{\circ} \mathrm{C} .{ }^{24}$ At $600^{\circ} \mathrm{C}$ Cyanoacrylate fuming, black magnetic powder, aluminium powder and Black Powder Suspension are not effective. ${ }^{43}$

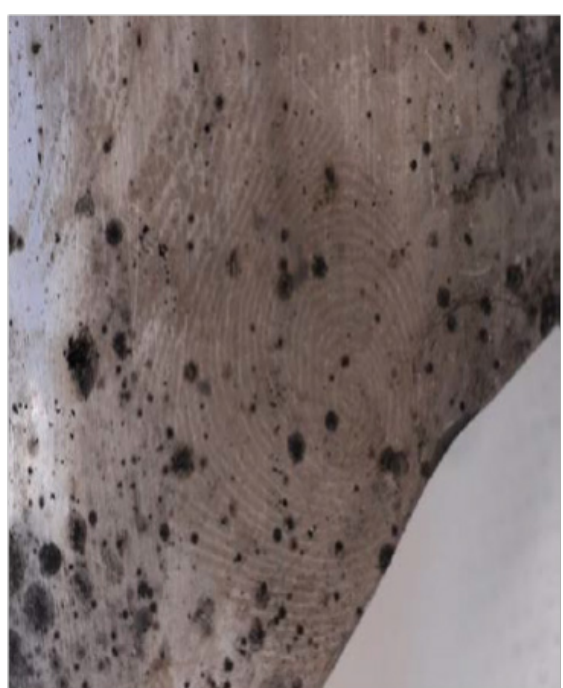

Figure 5 Fingerprint identified after soot removal with a soft brush. ${ }^{39}$

The possible exposure to water is a concern as the fingerprint may be further exposed to extreme conditions other than those of the fire.
It had been found that fingerprints can survive on items submerged in water for up to 15 days after deposition using Small Particle Reagent or Sudan black treatments. ${ }^{44}$ This is useful to be aware of as the fingerprint may have not been initially damaged by the heat, however, may possibly be damaged if submerged in water until the investigation team attend the scene. Madkour ${ }^{45}$ found the Cyanoacrylate fuming technique to be the most suitable technique for items submerged in fresh and salt water for up to 10 days. ${ }^{45}$ This disputes many other sources stating this technique cannot be used if the item have been wet. The longer the time before a fingerprint is treated, the higher the impact of degradation..$^{45}$ The components enhanced in cases regarding water submersion may be the components that are changed by the heat and may not be detectable after both exposures. For example, salt is able to withstand intense heat and is believed to be the most durable fingerprint component, however, it is water soluble so may be washed away if exposed to water during the extinguishing efforts.

Eviscan ${ }^{47}$ has produced a product able to scan soot covered items to detect fingerprints below the soot without chemical treatments or soot removal. It is an innovative German company claiming to be the first technology to detect, preserve and enhance latent fingerprints without the requirement for chemical treatment. This is achieved by non-contact methods. This method is beneficial as it does not risk destroying the fingerprint as contact methods often do. However, the equipment is non-portable and only works on smaller objects so cannot be used at the scene. Further research using this technique and further understanding of possibilities and limitations is required.

\section{Other factors to consider}

When an investigator is to consider a fire scene for fingerprints they must identify - areas or objects an offender may have touched; items out of place; items that can be used to cause damage by fire; areas protected from the direct effects of the fire such as items face down; items shielded by other items; and, areas with soot exposure but less intense heat. The fingerprint enhancement and soot removal treatment options can then be considered and whether entire scenes should be treated or specific sections. Predicted temperature exposure can aid the investigator to what chemical and soot removal treatments will be effective. Fingerprints at fire scenes are subjected to elevated temperatures, soot deposition, high pressure water and electromagnetic radiation. ${ }^{24}$ The extinguishing efforts play a key role in an arson investigation as it damages the scene further. It is important to understand what has been caused by the fire and what had been caused by the efforts to extinguish the fire. In a fire scene it is important to treat the surface below some items, for example, adhesive tape, as the effects of the fire commonly transfer the fingerprint to the surface to give a reversed print. ${ }^{30,17}$ As the exposure to the effects of the fire increase the opportunities for development decrease and further so if the item has been exposed to water. ${ }^{17}$ Fingerprints can be developed up to $800^{\circ} \mathrm{C}$, however, these opportunities are limited beyond exposure of $200^{\circ} \mathrm{C} .{ }^{30}$ The survival rate of the fingerprint is higher if the substrate has been protected. ${ }^{43}$

The temperature exposure a fingerprint will be suitable for enhancement will depend on the substrate. Glass is a suitable surface up to $800^{\circ} \mathrm{C}$, aluminium foil and black ceramic tiles are suitable up to $700^{\circ} \mathrm{C}$, white ceramic tiles and metal spoons are suitable until $600^{\circ} \mathrm{C}$, and tin cans are suitable up to $500^{\circ} \mathrm{C} .{ }^{46}$ Fingerprints made in blood and bloodstains on non-porous surfaces such as laminate flooring, glass, and ceramic tiles show complete destruction when exposed to elevated temperatures. Less damage can be observed on 
porous items including textured wallpaper, emulsion painted surfaces and semi porous gloss painted surfaces as the texture provided some protection..$^{34}$ It is also possible that the paint can partially melt and bind to the bloodstain. Dhall ${ }^{46}$ found that all the substrates tested were destroyed above $900^{\circ} \mathrm{C}$. Reverse development of a fingerprint made in blood has been observed on white glazed ceramic tiles at $700-900^{\circ} \mathrm{C}$ exposure as the ridges were darker than the background. ${ }^{26}$ Bradshaw $^{30}$ observed reverse development with powder as it settled in the furrows rather than on the ridges. Black magnetic powder is most suitable for this situation to decrease the effect of the prints being dotty and diffuse. Aluminium powder is less effective and stops working beyond $100^{\circ} \mathrm{C} .43,30$

Rehydration of the fingerprint by warm breath was recommended by Thornton \& Emmons ${ }^{32}$ to encourage dusting powder to better adhere to the fingerprint. Several studies found this to destroy the fingerprint and therefore this method is not recommended. It is recommended that exhibits are to be stored in a desiccator bag to prevent the fingerprint being exposed to moisture and destroyed. ${ }^{17}$ Alternatively, packaging of exhibits should be secure and rigid to prevent further damage. ${ }^{7}$ Care must be taken with metal items that have been found wet to avoid oxidation before they have been treated, they may need to be kept wet. ${ }^{6}$ It is possible a fire may simulate effects of a small explosion that may affect the fingerprint in different ways such as high pressure. Lanagan ${ }^{48}$ found only faint ridge detail using Cyanoacrylate fuming, Ultraviolet imaging systems and powder when exploring the effects of explosion. Sanders ${ }^{29}$ found that in an explosion study only five fingerprints showed friction ridge detail out of 42 tested. Dhall ${ }^{24}$ found that fingerprint recovery was not satisfactory in an explosion simulation and only found a partial fingerprint on an item that had been displaced from the initial blast and was not believed to have been exposed to the full effects of the destruction. Further research is required to understand how fingerprints behave in explosions.

Deans ${ }^{27}$ found that when a fingerprint was exposed to dry powder from a fire extinguisher the number of fingerprints detected by visual examination increased except on card when compared to foam or water extinguishing options. On some substrates, particularly the non-porous surfaces, it had the effect of developing the fingerprint. The dry powder did not affect the quality of the fingerprints for other enhancement techniques. The Aqueous Film Forming Foam had an opposite effect as it was the most detrimental extinguishing method to the deposited fingerprints. This is likely because contents such as water and surfactants can remove and dissolve the fingerprint constituents. ${ }^{27}$ The use of dry powder as an enhancement technique is effective on tile and glass surfaces but not suitable on metal surfaces or aluminium foil. ${ }^{49} \mathrm{~A}$ kitchen baster can be used if required to puff away excess powder deposits..$^{50}$ Dry powder is a suitable option as often there is easy access to dry powder fire extinguishers in a fire situation and does not require further enhancement or development. This does not require expert skill for application and is recommended to be sprayed from a distance of about one meter. ${ }^{50}$ This technique is suitable for large areas that require fingerprint treatment as an alternative to the powder and brush method. There is little risk of destroying the fingerprint through overdevelopment. It is efficient and not labour intensive. No further treatment is required and items do not need to be recovered to a laboratory. ${ }^{49}$

The dry powder is known as $\mathrm{ABC}$ powder and is based on Ammonium sulphate and/or Mono-ammonium phosphate. It can suppress the flame of the fire and it melts at a low temperature to create a slag layer to block heat transfer and exposure to gases. ${ }^{27}$ The powder fire extinguisher does not have a cooling effect by soaking into the materials and therefore the fire is at risk of re-ignition. ${ }^{51}$ The powder is versatile for fuel types compared with Aqueous Film Forming Foam and water options, however, it is not suitable for grease and cooking oil fires. ${ }^{52}$ The Aqueous Film Forming Foam is a synthetic foam concentrate mixed with water and air. ${ }^{27}$ The foam extinguishing method is suitable for solid combustible materials and flammable liquid fires. ${ }^{52}$ The foam penetrates a porous medium and has a cooling effect in addition to starving the flame of oxygen. ${ }^{51}$ This is relevant as the fire suppressing method can highly affect the potential of fingerprint recovery. In order to benefit forensic recovery of fingerprints without experiencing the damage observed from water methods it would be reasonable to recommend powder as a suppression method due to its versatility and properties less damaging to fingerprints. However, powder fire extinguishers are not recommended for use in confined spaces due to risk of inhalation and in addition, the clean-up efforts being complicated. ${ }^{51}$ Another consideration is the type of water that is used for extinguishing fires. Water with a higher salinity value than fresh water has a more detrimental effect on the quality of the fingerprint obtained. ${ }^{45}$

Some fingerprints will emit a weak luminescence. The source of this is unknown and believed to be from contamination to the natural eccrine secretion residues..$^{5}$ It is difficult to determine whether this would be affected from elevated temperatures. This may provide the investigator with information of the possible areas that may hold fingerprints and require further analysis. It is beneficial as few of the soot removal options were suitable for an entire scene. This luminescence may be excited in the blue-green region of the spectrum by use of a high-powered light source. Dried blood exhibits a strong absorption at $415 \mathrm{~nm}$ wavelength. ${ }^{5}$ This can also be used on fingerprints that have been developed by the soot. ${ }^{33}$

Ultraviolet high intensity light sources are beneficial to a fire scene as it is able to penetrate the soot and identify where fingerprints may lie. It is a non-invasive test that does not damage any further evidence in the process compared to other techniques. ${ }^{23}$ Success has been seen in identifying fingerprints exposed to intense heat and pressure with the use of a 'Reflected Ultraviolet Imaging System'. This technique is beneficial as it identifies topographical changes on the surface that become visible when viewed through the imager. The fingerprint can be captured through photography and may not require further analysis. ${ }^{53}$ Further research may be required to identify adaptations for a fire scene and how the technique deals with soot on top of the fingerprint deposit.

Infrared imaging can enable fingerprint visualisation through soot with a filter of $715 \mathrm{~nm}$ wavelength or above. This technique can be used in conjunction with other techniques such as Physical Developer when the developed components of the fingerprint remain in the infrared region (Figure 6). ${ }^{30}$

\section{Scenarios where the fire enhanced the fingerprint}

In some circumstances it has been recorded that theaction of the fire alone has enhanced the fingerprint. It has been observed that fingerprints from individuals with heavy eccrine secretions ('heavy donors') became visible on paper when exposed to beyond $200^{\circ} \mathrm{C}$ (Figure 7) ${ }^{17}$ In some situations soot and tar will deposit on the fingerprint ridges allowing the fingerprint to become developed by the fire itself. ${ }^{17}$ The fire may have contributed to the development of the fingerprint in the same way as the fingerprint visualisation technique 
known as the flame technique or soot deposition. These techniques involve igniting a small quantity of Camphor so it produces thick black smoke which deposits onto the item tested and the ridge detail of the fingerprint. The excess soot can then be brushed away using a feather brush to reveal a developed fingerprint..$^{54,25,10}$ Molten polymer fumes can be deposited on the fingerprint similar to the Cyanoacrylate fuming technique ${ }^{17}$ In a certain case there has been a circumstance when a fingerprint interacted with a plastic bowl believed to have been filled with gasoline by the offender. The gasoline was believed to have made the plastic partially soluble and caused the contact with the fingertip to form an impression. The bowl was unaffected by the fire elements and a silicone cast of the fingerprint impression was made by the investigators. ${ }^{55}$

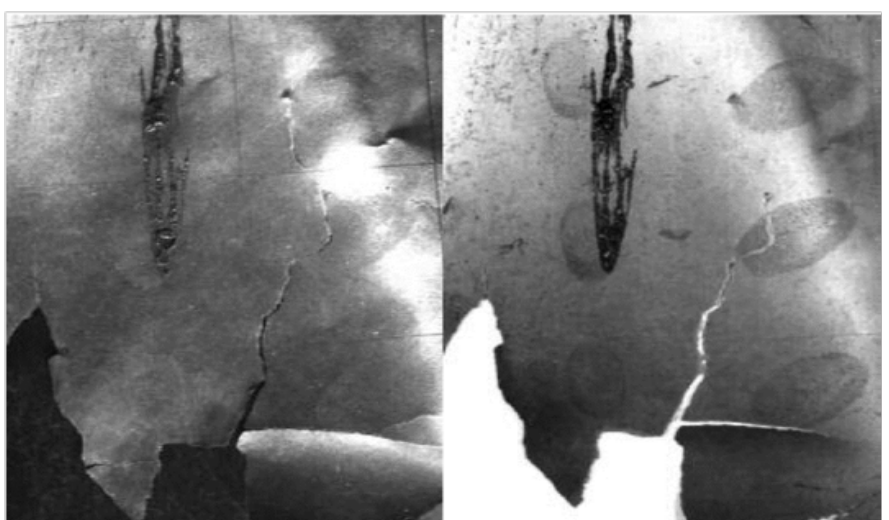

Figure 6 (Left) Photograph of charred paper. (Right) Fingerprints visualised on charred paper with infrared filter R G850.30

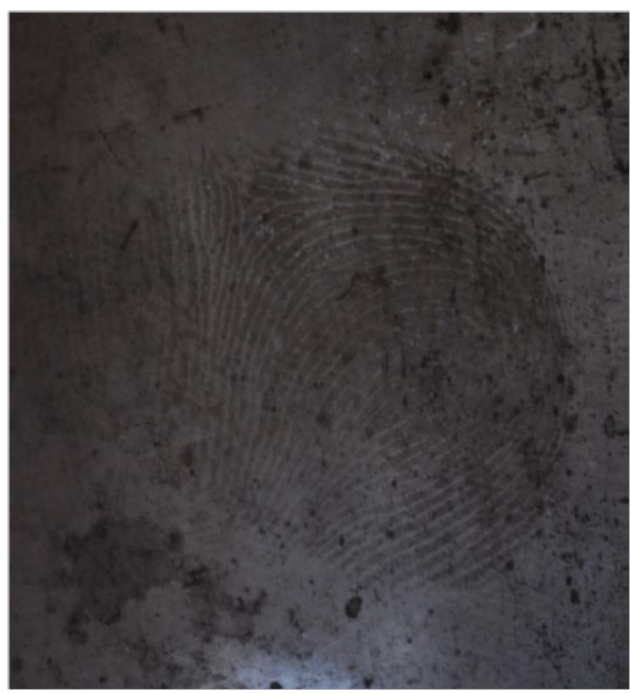

Figure 7 Fingerprint developed by sooty deposits in fire simulation during training activity. ${ }^{39}$

Metal surfaces may make the fingerprint visible when exposed to intense heat in an effect described as the fingerprint being 'baked on'. Galvanic corrosion can occur on the metal surfaces when the water components act as electrolytes. ${ }^{56}$ Bradshaw $^{17}$ found that fingerprints were visualised without development treatment and referred to as 'Baked on' on $30 \%$ of the metal plates tested. Copper becomes tarnished when exposed to elevated temperatures. The fingerprints from individuals with heavy fingerprint secretions can protect the surface from becoming tarnished allowing for the fingerprint to contrast the background of the substrate. ${ }^{17}$ Fingerprints made in blood on tin surfaces wet the surface and become 'baked on'. The opposite of this is seen with brass plates when the fingerprints made in blood pool together and a 'baked on' effect will not be seen. ${ }^{26}$ Spawn ${ }^{10}$ described a situation that a fingerprint had become baked onto a metal substrate when vigorous rubbing at the mark did not damage it (Figure 8).

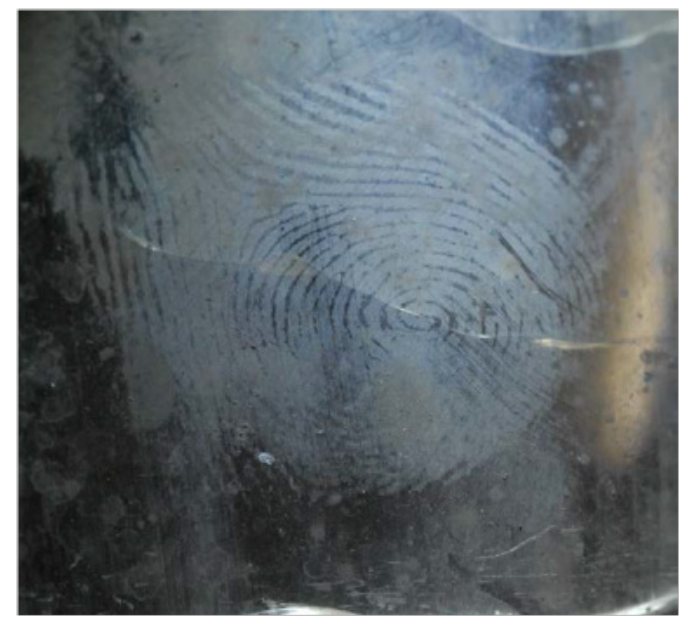

Figure 8 Fingerprint 'baked on' to metal surface, soot removed with soft eraser, identified during training activity. ${ }^{39}$

\section{Conclusion}

\section{Conclusion and recommendations}

It can be seen from Larkin ${ }^{33,57}$ that the recovery of fingerprints in an arson investigation is possible and has been performed in real cases. It confirms the work of other authors discussed in this paper that the possibility is present not only in theory, but, as well as in practice. It is understandable why fingerprint recovery within a fire scene is not at the forefront of forensic developments and evaluations. However, it is essential to maximise the potential to identify an individual related to the crime. It appears there is no soot removal technique or fingerprint development technique that will have a 'one solution to fix all approach'. The same can be said for the classification of arson and the way a fire may behave. A fire scene provides many uncertainties as no two fires are the same. With further research in the field an extensive guide can be produced to provide information to the fire investigation teams. In summary the most beneficial soot removal technique appears to be Liquid Latex, although, adaptations may need to be made dependant on the circumstances of the scene. Cyanoacrylate fuming is beneficial to non- porous items up to exposure of $500^{\circ} \mathrm{C}$, and Vacuum Metal Deposition is suitable up to $900^{\circ} \mathrm{C} .{ }^{30}$ Small Particle Reagent and Physical Developer are suitable for items that have been exposed to water. ${ }^{41}$ Further clarification of what techniques to use in different situations is required as many sources contain conflicted and contradictory information. Often the most obvious route of treatment cannot clearly be defined. Time and consideration will need to be taken to determine the most beneficial treatment route for the scene examination as some methods conflict with accelerant and DNA recovery.

It is important to note that in the production of this review paper the access to many of the reference papers involved was limited. 
Access to previous research and information regarding the recovery of fingerprints from a fire scene often proved difficult to obtain from both published documents and internet searches. The information described in the paper may not be readily available to the individuals investigating the scene. This may hamper the development of knowledge and hinder the recovery of fingerprints in an arson scene. Within police authorities there does not appear to be a standardised procedure relating to the recovery of fingerprints at a fire scene. Some authorities rarely attempt recovery of fingerprints at an arson scene. In future as information is shared, knowledge will evolve and standardisation of procedures will result. Advances in fingerprint enhancement techniques have been greatly beneficial to the field of forensic investigation with the Home of Scientific Development Branch leading the main advisory board for the UK police. In addition, the Forensic Science Service and research programs within various universities are constantly improving this field of knowledge. ${ }^{2}$ As with the development of standard fingerprint recovery, in the coming years it is expected that new developments and procedures will improve the use of fingerprint recovery in arson investigations.

\section{Acknowledgements}

None.

\section{Conflict of interest}

The authors declare no conflict of interest.

\section{References}

1. Caplan J, Torpey J. Documenting individual identity: the development of state practices in the modern world. Princeton, New Jersey: Princeton University press; 2001:173-177.

2. Frazer J, Williams R. Handbook of Forensic Science. Devon, England: Willian Publishing; 2009:696.

3. Jackson ARW, Jackson JM. Forensic Science. 3rd ed. Essex, England: Pearson Education Limited; 2011:544.

4. Harper W. Latent fingerprints at high temperatures. American Journal of Police Science. 1938;29(4):580-583.

5. Lennard C. Fingerprint detection: current capabilities. Australian Journal of Forensic Sciences. 2007;39(2):55-71.

6. Chisum WJ, Turvey BE. Crime reconstruction. 2nd ed. Waltham, MA Academic Press/Elsevier; 2011:704.

7. Icove DJ, Haynes GA. Kirk's Fire Investigation. 8th ed. NY: Pearson; 2018.

8. Gorbet GE, Meacham BJ, Wood CB, et al. Use of damage in fire investigation: a review of fire patterns analysis, research and future direction. Fire Science Reviews. 2015;4(4):2-35.

9. Silke MC, Brodbeck MD. The latex method for the recovery of blood, DNA and dermal ridge evidence in arson cases. Journal of Bloodstain analysis. 2011;27(4):3-7.

10. Spawn MA. Effects of fire on fingerprint evidence. The Spawn Group, LLC; 2015.

11. Home Office counting Rules for recorded crime: Arson and Criminal Damage; 2017

12. Dyson M. Blackstone's statutes on criminal law 2017-2018. 27th ed. 2017:480.
13. Pretious T. The investigation of fires where the supposed cause is not accidental. Fire and Rescue Service Circular. 2006.

14. Home Office. Fire statistics table 0102: Incidents attended by fire and rescue services by nation and population; 2017.

15. Home Office. Fire Statistics Table 0401: Deliberate fires attended by fire and rescue services in England, by Incident type and fire and Rescue Authority; 2017.

16. Office for National Statistics. Crime in England and Wales: Year ending September 2017, Statistical bulletin; 2017.

17. Bradshaw G, Bleay S, Deans J, et al. Recovery of Fingerprints from Arson Scenes: Part 1-Latent Fingerprints. Journal of Forensic Identification. 2008;58(1):54-82.

18. Harvey M. Crime Scene Investigation: Arson. 2018.

19. Office for National statistics. crime in England and wales: Year ending June 2015, statistical bulletin. 2015

20. Redsicker DR. Practical fire and arson investigation. 2nd ed. Boco Raton: CRC Press; 1997:432.

21. De Paoli G1, Lewis SA Sr, Schuette EL, et al. Photo-and thermaldegradation studies of select eccrine fingerprint constituents. J Forensic Sci. 2010;55(4):962-969.

22. Jasuja OP, Toofany MA, Singh G, et al. Dynamics of latent fingerprints: the effect of physical factors on quality of ninhydrin developed prints-a preliminary study. Sci Justice. 2009;49(1):8-11.

23. Stow KW, Mcgurry J. The recovery of finger marks from soot- covered glass fire debris. Sci Justice. 2006;46(1):3-14.

24. Dhall JK, Kapoor AK. Development of latent prints exposed to destructive crime scene conditions using wet powder suspensions. Egyptian Journal of Forensic Sciences.2016;6(4):396-404.

25. Clutter SW, Bailey R, Everly JC, et al. The use of liquid latex for soo removal from fire scenes and attempted fingerprint development with ninhydrin. J Forensic Sci. 2009;54(6):1332-1335.

26. Moore J, Bleay S, Deans J, et al. Recovery of fingerprints from arson scenes: Part 2 - fingerprints in blood. Journal of Forensic Identification. 2008;58(1):83-108.

27. Deans J, Cox M, Bleay SM. The effect of different types of fire extinguisher on the recovery of fingerprints. Fingerprint World. 2007;33(128):164 179.

28. Shaler RC. Crime scene forensics: a scientific method approach. Boca Raton; London: CRC; 2012.

29. Sanders N. Recovery of fingerprint evidence from post- blast device materials. Journal of forensic identification. 2011;61(3):281-295.

30. Bleay SM, Bradshaw G, Moore JE. Fingerprint Development and Imaging Newsletter: Special Edition. Home Office Scientific Development Branch. 2006;26(6):1-32.

31. Ahmad UK, Mei YS, Bahari MS, et al. The effectiveness of soot removal techniques for the recovery of fingerprints on glass fire debris in petrol bomb cases. Malaysian Journal of Analytical sciences. 2011;15(2):191201.

32. Thornton JE, Emmons BW. Development of latent prints in arson cases. Identification News. 1982;27(3):3-4.

33. Larkin TPB, Marsh NP, Larrigan PM. Using liquid latex to remove soot to facilitate fingerprint and bloodstain examinations: A case study. Journal of Forensic Identification. 2008;58(5):540-550. 
34. Luche C, Jordan R, Larkin T. Recovery of bloodstain patterns from arson scenes: does soot removal using liquid latex damage underlying bloodstains? Canadian Society of Forensic Science Journal. 2011;44(2):47-58.

35. Shelef R, Levy A, Rhima I. Recovery of latent fingerprints from soot covered incendiarized glass surfaces. Forensic Ident. 1996;64(5):565569 .

36. Gorn M, Stafford-Allen P, Stevenson J, et al. The recovery of footwear marks in blood at a homicide scene involving a smoldering fire. Journal of Forensic Identification. 2007;57(5):706-716.

37. McCloud VD. Processing glass bottles for latent prints in arson cases (Molotov cocktails). Identification News. 1978;28(11):5-6.

38. Tomboc R, Schrader M. Obtaining fingerprint and palm print impressions from decomposed bodies of burn victims using the Mikrosil casting method. Journal of forensic identification. 2005;55(4):471-479.

39. Smith SP. 'FI Evidence Lab Work Myths', Power Point presentation. Prometheus Forensic Services East Grinstead UK. 2016

40. Shelef R, Levy A, Rhima I. Development of Latent Fingerprints for Unignited Incendiary Bottles. Forensic Ident. 1996;46(5):557-560.

41. Kent T. Fingerprint development handbook. Police Scientific Development Branch, Crown Copyright, Derbyshire. 2000.

42. Sodhi GS, Kaur J. Physical developer method for detection of latent fingerprints: a review. Egyptian Journal of Forensic Sciences. 2015;6(2):44-47.

43. Gardner SJ, Cordingley TH, Francis SC. An investigation into effective methodologies for latent fingerprint enhancement on items recovered from fire. Sci Justice. 2016;56(4):241-246.

44. Castello A, Frances F, Verdu F. Solving underwater crimes: development of latent prints made on submerged objects. Sci Justice. 2013;53(3):328331

45. Madkour S, Sheta A, El Dine FB, et al. Development of Latent Fingerprints on Non-Porous Surfaces Recovered from Fresh and Sea Water. Egypt $J$ Forensic Sci. 2017;7(3):1-12.
46. Dhall JK, Sodhi GS, Kapoor AK. A novel method for the development of latent fingerprints recovered from arson simulation. Egyptian Journal of Forensic Sciences. 2013;3(4):99-103.

47. Eviscan.

48. Lanagan SR. Explosive effects on latent print evidence. Journal of forensic identification. 2006;56(1):18-23.

49. Piekny J, Knaap W. The use of a dry chemical fire extinguisher for the development of latent fingerprints in marijuana grow operations. Journal of forensic Identification. 2016;66(2):92-105.

50. Boateng JO, Jasra PK, Cowper D. Using dry fire extinguisher to develop latent fingerprints and its comparison with other methods of fingerprint development. Journal of forensic Identification. 2016;66(5):395-404

51. Fire Extinguishers. 2018.

52. Different types of fire extinguisher. 2018.

53. Gardner E. Using a reflected ultraviolet imaging system to recover friction ridge impressions on post-blast material. Journal of Forensic Identification. 2010;60(1):104-118.

54. Waldoch TL. The flame method of soot deposition for the development of latent prints on non-porous surfaces. Forensic Ident. 1993;43(5):463-465.

55. Tyranski W, Petraco N. An interesting arson case involving a plastic fingerprint. Identification News. 1981;31(6):6.

56. Gifei S. New techniques for raising and identification of fingerprints Union of Jurists of Romania. 2011;1(3):1-13.

57. Larkin TA. A case study of a dismemberment homicide scene subjected to an arson attack - soot removal techniques for BPA and fingerprin examinations. Proceedings of the 2006 international association of Blood Pattern analysis annual meeting. 2006. 